\title{
Erratum to: What Are the Real Procedural Costs of Bariatric Surgery? A Systematic Literature Review of Published Cost Analyses
}

\author{
Brett Doble $^{1}$ - Sarah Wordsworth ${ }^{1} \cdot$ Chris A. Rogers ${ }^{2} \cdot$ Richard Welbourn $^{3}$. \\ James Byrne ${ }^{4}$ - Jane M. Blazeby ${ }^{5}$ - By-Band-Sleeve Trial Management Group
}

Published online: 9 June 2017

(C) Springer Science+Business Media New York 2017

Erratum to: OBES SURG

DOI 10.1007/s11695-017-2749-8

In the original version of this article there was a typographical error in the author group. The author group is correct as reflected in this erratum. The original article has also been updated.

The online version of the original article can be found at http://dx.doi.org/ $10.1007 / \mathrm{s} 11695-017-2749-8$

Brett Doble

brett.doble@dph.ox.ac.uk

1 Health Economics Research Centre, Nuffield Department of Population Health, University of Oxford, Oxford OX3 7LF, UK

2 Clinical Trials and Evaluation Unit, School of Clinical Sciences, University of Bristol, Bristol BS2 8HW, UK

3 Department of Upper Gastrointestinal and Bariatric Surgery, Musgrove Park Hospital, Taunton TA1 5DA, UK

4 Southampton University Hospitals NHS Trust, Southampton SO16 6YD, UK

5 Bristol Centre for Surgical Research, School of Social and Community Medicine, University of Bristol, Bristol BS8 2PS, UK 